\title{
DEVELOPMENT OF MUSIC TEACHER'S REFLECTIVE ACTIVITY: THEORETICAL ASPECT
}

\section{Summary}

\section{Introduction}

Today we can see the striking contradiction: on the one hand, there is a demand for specialists, who are ready to start their professional activity without a long period of adaptation, and who could act in swiftly changing conditions of educational environment; on the other hand, the level of organisation of the professional competence in the field of reflective activity is not high enough.

\section{Aim of the Study}

To identify and analyze emerging trends and conceptions in development of teacher's reflective activity, as well as to outline the approaches in the pedagogical and psychological sciences about the problem of reflection in the teacher's creative activity.

\section{Materials and Methods}

The following research methods have been used: the analyses and comparison of pedagogical and psychological conceptions.

\section{Results}

In the study process the following directions of reflective processes in the music teacher's practice were distinguished: in the attempt of understanding and purposeful regulation of thoughts, feelings and deeds of the student; in the process of projecting the student's practice; in the process of reflective analysis and self-regulation; in the process of stimulating the student's own reflective activity.

\section{Conclusions}

The activization of reflective position in creative pedagogical activity is connected with the teacher's personality, with his/her orientations towards self-development. The music teachers' involvement into the analysis of contradictions, giving them the opportunity to identify and choose the meaning of these or those pedagogical actions, approaches, conceptions are the starting points of the development music teachers' reflective and methodological culture, which expresses both their personality position and the reflective and creative side of their professional development.

Key words: music teacher's reflective activity, pedagogical activity, reflective skills, reflective culture.

\section{Introduction}

We are living in the epoch of global changes in the society. In the field of pedagogy this is a transition to the new optimal psychological-pedagogical systems, the creative technologies of teaching. The humanistic model of music education is defined by such principal functions of pedagogical activity as the social - cultural values and the development of creative activity of the student. The main results of pedagogical activity are the formation of new mental growths of the learner's personality and the improvement of the ways of his activity, which ensures his successful entry into new pedagogical situations, quick adaptation to new requirements, and the ability to 
solve new tasks.

Transformation of the educational system has the tendency of changing from reproductive into constantly developing and open. Students' involvement in the solution of their own educational and socio-cultural problems demands reforming the system of higher professional education; it is also necessary to change the attitude to pedagogical teaching practice.

Now the goal of educational process is not mastering in ready knowledge; it is mastering in a certain way of thinking, which provides gaining and producing the new knowledge (Lisle, 2006).

Introducing different innovations in the process of development of modern education entails reconsideration of the whole row of principal positions, for example, what and how the modern specialists should be taught. Intensively developing innovative educational systems have high demands, first of all to teachers' creative individuality and creativity.

Today we can see the striking contradiction: on the one hand, there is a demand for specialists, who are ready to start their professional activity without a long period of adaptation, and who could act in swiftly changing conditions of educational environment; on the other hand, the level of organisation of the professional competence in the field of reflective activity is not high enough. We often observe a low level of reflection of many Latvian music teachers, which hinders their professional skills development (Davidova, 2000).

Some Russian scholars also note a low level of the teachers' pedagogical reflection, who are often orientated towards their own learning experience (not always successful), who are not objective in their assessment, who blame the learners, the administration, the economic conditions, etc. for failure (Skok, 1998).

A low level of reflection is often related to being unaware of difficulties in the pedagogical activity both in the field of the study process projecting and in communication with the learners.

Some of the questions raised here are:

- What does teacher's reflective activity mean?

- How can a music teacher develop reflective abilities?

\section{Aim of the Study}

To identify and analyze emerging trends and conceptions in development of teacher's reflective activity, as well as to outline the approaches in the pedagogical and psychological sciences about the problem of reflection in the teacher's creative activity.

\section{Materials and Methods}

The analyses and comparison of pedagogical and psychological conceptions.

\section{A) Pedagogical creative activity as a system with reflection}

In accordance with the general regularities of the human psychical functioning, the teacher's consciousness is constantly acting in two directions: outside, i.e. being aimed at the dialogue with students, and inside, at the dialogue with oneself, acting in this case as an instrument of self-knowledge. The guidance of these processes is carried out not only by the central "I" of the personality, the function of which includes the elaboration of the general strategy of the teacher's activity and behaviour. The reflexive "I" (from Latin reflexus - an appeal backwards, reflection), aimed inside to self-regulation, control, evaluation and correction of the actions performed, and the activity "I", whose direct task is the practical realization of the pedagogical aims, are involved here simultaneously.

The necessity of studying professional self-knowledge, i.e. being aware of oneself as a personality in professional activity, including teacher's professional activity (alongside with the general principles and regularities of the personality self-awareness development), has been 
repeatedly emphasised in modern psychological and pedagogical literature. According to S. Rubinstein, reflection provides "the exit out of full absorption in the direct process of life for working out the corresponding attitude towards life, taking the position above it, beyond it for judgement about it" (Rubinstein, 1976).

The problem of reflection is many-sided and diverse: it has philosophical, psychological, pedagogical, methodological and other aspects (Adler, 1991; Petrovsky 1996; Vishnjakova 1999; Kashapov 2000; Stepanov 2000; Lefevr, 2003; Slastenin, 2005; Heikkila, Lonka, 2006 etc.).

Numerous recent research works in music pedagogy underline the necessity of actualisation of the reflective character of professional creative practice of music teachers, as well as training to implement this practice (Hallam, 1998, 2006; Bochkarev, 1997; Petrushin, 1997; Podurovsky, 2001; Kauzova, Nikolajeva, 2001; Cipin, 2003; Ward, 2004 etc.).

Reflection (from Latin reflexio - conversion back) is the process of understanding something by means of learning and comparison. In the narrow sense it is "a new turning" of the spirit after performing the learning act to I (as the centre of the act) and to one's microcosm; and due to that appropriation of the learnt material is possible (Gubsky, Korablova, Lutchenko, 1994).

In the broad sense-going reflection as a process is out of the borders of any direct, automatically going process or condition. In the narrow sense it is reflecting one's own activity, looking back, into the "inside" of the activity, with the aim of its developing, i.e. research position in any activity (Maralov, 2004).

Reflection as a quality is the ability of the consciousness to be focused not on the object of the activity, but on the activity itself; the specific human ability to treat one's own thoughts, emotional conditions, deeds and attitudes, and himself in general, like the object of specific consideration (analysis and evaluation), and the ability of transformation (Sergejev, 2004).

Traditionally, in psychology, there is a division into several types of reflection:

- Communicative, which object is understanding of the other person's inner world and the causes of his/her deeds;

- Personal, which object is learning of one's own learning personality, his/her characteristics and qualities, behavioural characteristics, the system of treating other people;

- Intellectual, which can bee seen in the process of solving the tasks of different types, in the ability to analyse different ways of decisions, in finding the most rational decisions, and repeatedly return to the conditions of the task.

In psychological and pedagogical researches reflection is applied mostly in intellectual way as a component of creative thinking; the functioning of creative thinking is ensured by controlling and evaluating one's own deeds. And it is also used in a personal way: as self-consciousness, selfanalysis, which is connected with communication in a dialogue and reflective expectations.

Pedagogical reflection is the ability and need to learn, to understand one's own conditions, to compare tasks, deeds and achieved results in real pedagogical situations with the aim of control, evaluation, correction and development of one's pedagogical practice and communication.

Reflection has been studied in the most serious and many-sided way in the works devoted to the revelation of creative task solution mechanisms. It should be noted, that many authors distinguish two close concepts - "reflection" and "reflexivity". Thus, D. Shön considers that reflection is the process in which "knowledge-in-action" may be more pronounced. It may be pronounced to the extent that the direction of attention towards control in the process of activity is possible. This form of reflection may be achieved by creating probable situations, within the limits of which separate aspects of activity may be analysed, traced and presented on a more conscious level (Shön, 1983). 
However, as noted by V. Richardson, this process is not a simple one: it may not be possible for a practitioner to describe the decision, making processes that led to an action. The concept of "knowledge-in-action" can be seen as descriptive rather than prescriptive. This process does not only create certain requirements in relation to creative work and inventiveness, but it may also depend on the existence of knowledge base received in the result of an experiment (Richardson, 1990).

As regards the term "reflexivity", many authors accept the Latin definition of this term (return to yourself), which means the process of individual's thought about what is going on in his/her own mind (Lawson, 1985; Steier, 1991; Bourdieu, Wacquant, 1992; Matthews, Jassel, 1998). On this basis of the analysis and comparison of different conceptions with regard to such notions as "reflection" and "reflexivity", we consider reflection as a process and reflexivity as an emotional state.

The notion about pedagogical activity as creative activity, comprising potential abilities and reserves of changing the personality, is supplemented by understanding the activity as the system with reflection and reflexivity.

Reflection is a central mechanism of implementing creative ability. Creativity is the necessary condition of pedagogical process, objective professional necessity of teaching practice (Mitina, 2004). Creativity is the most vital and necessary feature of pedagogical practice. This is the ability to see, put and solve pedagogical tasks in original way, to understand and quickly react to arisen pedagogical situations, to foresee the results; this is the main parameter of pedagogical creative abilities. It means that creativity of pedagogical practice is based on reflecting, reflective ability and practice.

In many philosophical and pedagogical papers it is spoken about the interrelation of creative activity and reflection (Schőn, 1983; Lawson, 1985; Davidov, 1989; Adler, 1991 etc.).

M. Holly is convinced that teachers have to "carefully, cautiously and inexorably tug at and remove our blindfolds and to explore and learn about the territory our personal and professional selves so guardedly inhabit" (Holly, 1993). Further, M. Holly says that the more teachers are able to understand the patterns of emotion that structure their patterns of behaviour in the classroom, the more this self-understanding can enable them to become better teachers. Teachers will be less caught in espousal of norms and stereotype actions, and more able to develop through critical analysis and self-control. This understanding includes the knowledge which determines the connection between one's own "self", beliefs, values, doubts - that knowledge which mainly refers to one's own personality.

B. Matthews and J. Jassel note that in teacher's creative activity the reflective act may be expressed in the following way: the teacher correlates a concrete pedagogical situation with his/ her past experience, as well as with the help of self-analysis he/she can explain some aspects and determine the interrelations of his/her assumptions about students with his/her actions in the classroom (Matthews, Jassel, 1998). It is such understanding that becomes the starting point of creative pedagogical activity: "Under the conditions of reflective interaction one of the subjects outstrips the other's reflection-forecasts the other's thoughts and behaviour several steps ahead (records his own and other's actual and potential capabilities), has more chance for success" (Slastenin, Podimova, 1997).

One should not confuse reflection and introspection (from Latin intro - inside, and specto - I am looking, peering), treating it as a passive process of self-observation. In its essence, reflection is an active instrument of organization of one's own activity, the means of its regulation and improvement. It allows the teacher not only to govern his realization actions, but also simultaneously 
to evaluate objectively their actual results, which facilitates the effectiveness of the study process.

Different levels of creative pedagogical activity are determined by different content of reflective activity. Thus, the content of the process of goal setting is determined by the results of reflection on motivation sphere (the knowledge about the motive leads to building up the aim). The subject's activity is possible when he has/she the model, the plan of activity implementation built up in the result of reflection on goal setting. The reflective activity on processes and components of activity is getting still more complicated, since the record of activity results and their correlation with the forecast aim (the activity evaluation), with the content of the image "self" and other elements of "self"-conception (self-assessment) is necessary.

Reflection on goal setting in teacher's creative activity has the following characteristics:

- A direct analysis - goal setting from the actual state of the pedagogical system to the final planned aim;

- A reverse analysis - goal setting from the final state to the actual state;

- A goal setting from intermediate aims with the help of both direct and reverse analysis (Slastenin, Podimova, 1997).

V. Slastenin and L. Podimova note that the teacher's possibility to implement goal setting freely and to be aware of its expediency depends on the following conditions:

- On the level of awareness and management of the processes of goal setting, as well as on the analysis of these processes, which gives the teacher an opportunity "to see" himself/herself on the way of building up the pedagogical conception, as well as to realize the limits of his/her states and actions more clearly;

- On the ability to identify the importance of the creative activity motive for learners and for himself/herself;

- On the ability to build the optimal algorithms of creative activity for achieving the aim;

- On the teacher's confidence, flexibility and activity adequacy, while analysing and assessing the results and consequences of achieving the aim (Slastenin, Podimova, 1997).

Analysing different approaches to the problem of the concept "reflection" one should point to the existence of two traditions in the interpretation of reflective processes:

- The reflective analysis of consciousness leading to the explanation of the meanings of objects;

- Reflection as understanding the sense of interpersonal communication.

In relation to this, it is necessary to single out such reflective processes as self-understanding and understanding others, self-assessment and assessment of others.

\section{B) Developing music teacher's reflective abilities}

The activization of reflective position in creative pedagogical activity is connected with the music teacher's personality, with his/her orientation towards self-development. The source of this process appears to be the system of contradictions in pedagogical activity, which the teacher is aware of.

Reflective activity, as the music teacher's cognition and analysis of phenomena of this own consciousness and actions, is the most important and essential component in the structure of creative pedagogical activity (Davidova, Znutinsh, 2001). Reflective skills are related to the teacher's skill to take into account his/her own individual psychological peculiarities, to adequately estimate his mental state, as well as to carry out many-sided perception and adequate cognition of the learner's personality.

Therefore, in the process of music teacher's training it is necessary to create such situations, which would actualise the reflective position, would form positive self-perception, and would stimulate the processes of self-assertion. 
Planning the strategies of the music thinking, a teacher create situations, in which the student shouldn't copy the interpretation of the others, he/she should create his/her own interpretation. It is necessary to plunge him/her in the world of style and meaning, into learning of its essence. And on the basis of its understanding and rethinking there will be a possibility to activate the creative power, to find his/her personal forms of its embodiment in sounds.

Reflective processes in the music teacher's practice can be seen in the following directions:

- in the attempt of understanding and purposeful regulation of thoughts, feelings and deeds of the student;

- in the process of projecting the student's practice;

- in the process of reflective analysis and self-regulation;

- in the process of stimulating the student's own reflective activity.

The following aspects can be pointed out in the music teacher's reflective practice:

- the interest to a problem of music pedagogy;

- finding, judgement and evaluation of the contradictions existing in the basis of the problem;

- looking for the foundations and possible variants of its solving, comparing the contents of the music-pedagogical task with one's own individual, personal and professional experience, as well as with the experience of other pedagogues - musicians;

- implementation of practical, logical-constructive activities, which provides him/her with successful solution of music-pedagogical tasks;

- generalizing evaluation of all the previous stages of reflective practice by the music teacher, which leads to its enrichment and leading it on the meta-level and to the merge with a new cycle of its implementation.

In this given context there is the main logical direction: from broad, generalized judgements of solving difficulties (i.e. judgement of music-pedagogical problems) to the concrete ways of overcoming the contradictions.

I.S. Sergejev notes the following reflective and creative abilities, which must be mastered by the teacher:

- the ability to understand the task, which contains such aspects that the person does not have enough knowledge to solve them;

- the ability to answer the question What do I need to learn in order to solve the given task?;

- the ability to evaluate knowledge towards the concrete pedagogical situation;

- the ability to point out the task out of the background;

- the ability to analyse the problematic situations (finding and solution of the contradictions);

- the ability to see and find original ways of the task solution;

- the ability to solve non standard tasks, which algorithms of solving have not been studied;

- the ability to divide the new task into subtasks, the solving of which has been studied;

- the ability to put the task, the solution of which presupposes the use of non standard ways;

- the ability to follow the chosen position to the problem;

- the ability to solve the tasks, where the final aim and ways of its achievement do not exist;

- the ability to change the point of view on the object (phenomenon) to the polar one, and to find the arguments pros and cons in both positions (Sergejev, 2004).

Mastering the system of means and ways of solutions of pedagogical tasks by the teacher, the skill to understand the core of the phenomena promotes the formation of pedagogical thinking and self-analysis develops pedagogical reflection.

If the teacher wants to master the professional-pedagogical culture, first of all, he/she needs 
to understand and reflect pedagogical practice as on the creative process:

- Reflective output: it is applied when by other means it is impossible to understand the other person or oneself;

- Intentionality (intention - direction): direction to the object of reflection, pointing it out from the other objects;

- Primary categorisation: the choice of primary means, in order to implement reflection;

- Constructing the system of reflective means: the chosen primary means get united in a system, which gives the possibility to check the reflecting analysis more purposefully;

- Schematization of reflective contents: it is made by using different signs (images, symbols, schemes, language constructions etc.);

- Objectivization of reflective description: evaluation and discussion of the given result (Maralov, 2004).

According to G. Cipin, the theoretical model of reflective activities is the following:

1. Determining the aim, more or less clear understanding of it;

2. Determining the primary tasks, which must be done in order to achieve the aim;

3. Practical implementation of what has been planned; planning the further actions; the choice of adequate means, which are necessary in order to implement one's intentions;

4. Correction of the actions, inserting the necessary situational changes, corrections and additions into them; flexibility of behavioural tactics;

5. Completing the way. Evaluation of the given results and self-evaluation of one's own actions. If necessary, starting anew, following the mentioned-above scheme, i.e. transition to a new cycle of the activity (Cipin, 2003).

V. Slastenin distinguishes the following most important criteria of development of teacher's reflective culture:

- Presence of conception about reflective guiding lines in life, as well as in pedagogical profession;

- Striving for understanding and rethinking of personal and professional orientation in his/her life course;

- Creating his/her own reflective models of the future professional practice and life in general;

- Reflection on the growth of the status in personal and professional aspects, aspiration to understand his/her own personality and professional individuality;

- Implementing individual reflective programs of personal and professional self-development (Slastenin, 2005).

\section{Results}

On the basis of the mentioned above criteria of reflective culture, author points out six levels of the process of forming and developing reflective practice:

- Zero level: it is characterized by the absence of the need in reflecting personal and professional self-defining and self-developing.

- Conventional level: the lowest level, which is directed to generally accepted (conventional) social-professional norms and criteria of development of reflective culture.

- Intentional level: a low level of development of reflective culture, the presence of reflective intentions - the will and aspiration to understand and rethink about the personal and professional peculiarities, values and orientations of one's own personality, about one's own professional way and life way.

- Potential level: the average level of development of reflective culture. It is characterized by the use of reflective-creative personal potential, by the formed reflection and independent creative 
putting and professional solution of theoretical-applicable tasks, by developing the project culture and reflective-transforming attitude to one's own life in general as well as to teaching and professional work.

- Possidentional level: the high level of development of reflective culture. It is characterized by the high level of understanding and judgement of the current level of development of reflective qualities and abilities, by aspiration to reflect on teacher's own personal and professional individuality. On this level the complete reflective position of the subject as a personality and a specialist gets formed and developed.

- Creative level: the highest level of development of reflective culture. On this level reflectivecreative potential of a person gets fully implemented, which results in the process of one's "uniqualization" of the subject with the self-developing system of personal and professional values (Slastenin, 2005).

The process of forming reflective culture of the teacher reflects the logic of developing of the subject and goes through the following stages:

1. The object stage includes technological approaches and means of activating the student's reflective mechanisms.

2. The object-subject stage, where the student is taught the rudiments of reflective practice.

3. The subject-object stage, where get formed the following components of the student's reflexive culture: readiness for independent preparation and solution of pedagogical tasks.

4. The one's own subjective stage includes teaching the student the practical rudiments of implementing individual reflective programmes of personal-professional self-development.

\section{Conclusions}

1. New strategic guidelines in developing the society and higher education are conditioned by the necessity of searching for such approaches to practice of future teachers' training, which could shape the specialist of the new type, i.e. the pedagogue-researcher, who is ready for innovative activity, as well as for participation in research activity. The new quality of training the specialist in the field of education must be determined not only by readiness to apply in practice the known ways of solving pedagogical problems, but by the ability to independent projecting pedagogical systems, processes and situations.

2. Analysing different approaches to the problem of the concept "reflection" one should point to the existence of two traditions in the interpretation of reflective processes:

- The reflective analysis of consciousness leading to the explanation of the meanings of objects;

- Reflection as understanding the sense of interpersonal communication.

3. Reflection is one of the mechanisms, which lets the music teacher to be a strategist in professional practice. Its importance is firstly caused by the fact that in the process of reflecting the factors of music-pedagogical reality by the teacher, appears and gets created the individual personalprofessional concept, as well as the system of moral-professional aims, norms, requirements, principles and values. The teacher's reflective activity is a polysemantic notion, including the teacher's knowledge analysis both of his/her own personality and pedagogical activity, and of the learner's personality and the study process peculiarities of the concrete class, with the aim of the learner's personality development on the basis of the study process humanization.

4. The presence of professional reflection gives the music teacher a possibility to implement a transition from the position of the music teacher as a practitioner of students' activity on the basis of the specific contents of the subject, as well as on the forms and methods of teaching, i.e. 
to the position of the teacher-researcher of his/her own professional practice as a special object of analysis, understanding and evaluation. It promotes his/her professional development and the results of his/her professional practice get better.

5. The necessity for the teacher to form his/her reflective skills ensures him/her independence in solution of the following basic problems:

- determining the borders of one's own knowledge and skills, which let effectively solve specific teaching-creative tasks;

- understanding the possibility of independent search for ways and means of arisen tasks;

- evaluation of the qualitative level of activities, which ensures solution of the given task.

6. With the development of the music teacher's ability to reflect, the sphere of his/her learning practice includes not only the subject contents of general cultural values and norms, but it also includes the thinking activity itself, in the process of which these values and norms get worked out.

7. The music teachers' involvement into the analysis of contradictions, giving them the opportunity to identify and choose the meaning of these or those pedagogical actions, approaches, conceptions are the starting points of the development music teachers' reflective and methodological culture, which expresses both their personality position and the reflective and creative side of their professional development.

\section{REFERENCES}

1. Adler S. (1991) The Reflective practitioner and curriculum of teacher education. Journal of Education for Teaching, 17 (2), p. 139-150.

2. Bochkarev L (1997) Psychology of Music Activity. Moscow: Institute of Psychology RAN, 350 p. (in Russian).

3. Bourdieu P., Wacquqnt L. (1992) An Invitation to Reflexive Sociology. Oxford: Polity Press, 246 p.

4. Cipin G. M. (Ed.) (2003) Psychology of Music Activity: Theory and practice. Moscow: Publishing Centre "Academia", 368 p. (in Russian).

5. Davidov V. V. (1989) The Developing Teaching. Moscow: Pedagogy, 213 p. (in Russian).

6. Davidova J. (2000) The Development of Future Teacher's Reflective Activity. In: Today's Reforms for Tomorrow's School's: ATEE Spring University 2000. Klaipeda: Klaipedas universitetas, p. 54-58.

7. Davidova J., Znutinsh E. (2001) The Music Teacher's Professional Development in Different Kinds of Pedagogical Activity: Paper presented at The Second International Research in Music Education Conference. Exeter, United Kingdom, 3-7 April, 2001, p. 45-53.

8. Gubsky J. F., Korablova G. V., Lutchenko V. A. (1994) Brief Philosophical Encyclopaedia. Moscow: Publishing Group Progress, 576 p. (in Russian).

9. Hallam S. (1998) Instrumental Teaching. Oxford: Biddles Ltd. 350 p.

10. Hallam S. (2006) Music Psychology in Education. London: University of London. 281 p.

11. Heikkila A., Lonka K. (2006) Studying in Higher Education: Student's Approaches to Learning, SelfRegulation, and Cognitive Strategies. Studies in Higher Education, 31, p. 99-117.

12. Holly M. (1993) Personal and Professional Knowledge: On Teaching and Self - knowledge. In: Plummer G., Edwards G. (Eds.) Dimensions of Action Research: People, Practice and Power. Poole: Hyde Publications, p. 275-294.

13. Kashapov M. M. (2000) Psychology of Pedagogical Thinking. Saint-Petersburg: Aleteja, 463 p. (in Russian). 
14. Kauzova A. G., Nikolajeva A. I. (Eds.) (2001) Theory and Methodology of Teaching Piano. Moscow: Publishing Humanitarian Centre "Vlados", 368 p. (in Russian).

15. Lawson H. (1985) Reflexivity: The Post-modern Predicament. London: Hutchinson, 259 p.

16. Lefevr V. A. (2003) Reflection. Moscow: Cogito Centre. 496 p. (in Russian).

17. Lisle A. (2006) Maintaining Interaction at the Zone of Proximal Development: Through Reflexive Practice and Action Research. Teacher Development, 10, p. 117-143.

18. Maralov V. T. (2004) The Basis of Self-cognition and Self-development. Moscow: Publishing Centre "Academy”, 256 p. (in Russian).

19. Matthews B., Jassel J. (1998) Reflective and Reflexive Practice. Teaching in Higher Education, 3(2), p. 231-243.

20. Mitina L. M. (2004) Psychology of Labour and Teacher Professional Development. Moscow: Publishing Centre "Academy", 316 p. (in Russian).

21. Petrushin V. I. (1997) Music Psychology. Moscow: Publishing Humanitarian Centre "Vlados", 384 p. (in Russian).

22. Podurovsky V. M., Suslova N. V. (2001) Psychological Correction of Music-Pedagogical Activity. Moscow: Publishing Humanitarian Centre "Vlados", 320 p. (in Russian).

23. Richardson V. (1990) The Evolution of Reflective Teaching and Teacher Education. In: Clift R. T., Haiston W. R., Pugach M. C. (Eds.) Encouraging Reflective Practice in Education. New York: State University of New York Press, p. 58-86.

24. Rubinstein S. (1976) Problems of General Psychology. Moscow: Science, 348 lpp. (in Russian).

25. Sergejev I. S. (2004) The Rudiments of Pedagogical Activity. Saint-Petersburg: Piter, 316 p.

26. Shön D. A. (1983) The Reflective Practitioner: How Professionals think in Action. New York: Basic Books.

27. Skok Y. B. (1998) How to Analyse Your Own Pedagogical Activity. Moscow: Russian Pedagogical Agency, 112 p. (in Russian).

28. Slastenin V. A. (2005) Reflective Culture and Teacher's Professionalism. Pedagogical Education and Science, 3, p. 37-42. (in Russian).

29. Slastenin V. A., Podimova L. S. (1997) Pedagogy: Innovative Activity. Moscow: Publishing House "Magistr", 224 p. (in Russian).

30. Steier F. (Ed.) (1991) Research and Reflexivity. London: Sage, 315 p.

31. Stepanov S. J. (2000) Reflective Practice of Creative Development for People and Organisations. Moscow: Science, 174 p. (in Russian).

32. Vishnjakova N. F. (1999) Creative Acmeology. 2nd Edition. Minsk: Debor, 300 p. (in Russian).

33. Ward V. (2004) The Performance Teacher as Music Analyst: A Case Study. International Journal of Music Education, 22 (3), p. 248-265.

Professor Dr. paed. Jel̦ena Davidova

Lecturer Mg. paed. Tatjana Minakova

Daugavpils University

Address: Jātnieku 42A-29, Daugavpils, LV-5404, Latvia

Phone: +37129140287

E-mail: jelena.davidova@du.lv; tatjanaart@,rambler.ru 